\title{
Triptofano na alimentação de codornas japonesas nas fases de recria e postura $^{1}$
}

\author{
Pricila Vetrano Rizzo ${ }^{2}$, Gisele Cristina Guandolini ${ }^{3}$, Lizandra Amoroso ${ }^{4}$, Ramon Diniz \\ Malheiros $^{5}$, Vera Maria Barbosa de Moraes $^{6}$
}

\author{
1 Projeto financiado pela FAPESP. \\ 2 Mestranda em Ciência Animal e Pastagens - ESALQ/USP. Bolsista FAPESP. \\ ${ }^{3}$ Mestranda em Psicobiologia - FFCLRP/USP - Bolsista CNPq. \\ ${ }^{4}$ Doutoranda em Zootecnia - FCAVIUNESP. \\ ${ }^{5}$ Campus Experimental de Dracena - UNESP. \\ ${ }^{6}$ Departamento de Zootecnia da FCAVIUNESP, Via de acesso Prof. Dr. Paulo Donato Castellani, s/n, CEP: 14884-900, Jaboticabal-SP.
}

RESUMO - Objetivou-se estudar o efeito de diferentes planos alimentares, de acordo com os níveis de triptofano, sobre o desempenho e estresse (pela avaliação de parâmetros fisiológicos) de codornas japonesas (Coturnix coturnix japonica) nas fases de recria e postura. Cento e noventa e duas codornas japonesas na fase de recria (30 a 44 dias de idade) foram alojadas em gaiolas e distribuídas em um delineamento em blocos casualizados, com quatro planos de nutrição [0,27 (controle); 0,52; 0,77 ou $1,02 \%$ de triptofano], seis repetições e oito aves por parcela. Foram avaliados os parâmetros de desempenho (consumo de ração, ganho de médio peso, conversão alimentar e taxa de mortalidade) e os parâmetros fisiológicos das aves (relação heterófilo/linfócito e concentração de corticosterona no plasma sangüíneo). Outras 192 codornas japonesas na fase de postura (45 a 146 dias) foram distribuídas em delineamento de blocos ao acaso e submetidas a quatro planos de nutrição (0,23 [controle]; 0,$48 ; 0,73$ ou $0,98 \%$ de triptofano), com seis repetições e oito aves por parcela. Foram avaliados o consumo de ração, a produção de ovos, a conversão alimentar por dúzia de ovos, a taxa de mortalidade, a relação heterófilo/linfócito e a concentração de corticosterona no plasma. Os níveis de triptofano testados não afetaram o desempenho e os parâmetros fisiológicos de codornas japonesas nas fases de recria e postura.

Palavras-chave: corticosterona, Coturnix coturnix japonica, desempenho, estresse, relação heterófilo/linfócito

\section{Tryptophan in the Japanese quails diets in the rearing and laying periods}

\begin{abstract}
The effects of feeding levels of tryptophan on performance and stress of Japanese quails (Coturnix coturnix japonica) in the rearing and laying periods were evaluated. In the rearing phase, from 30 to 44 days old, 192 Japanese quails were lodged to cages and allotted to completely randomized blocks design, with four nutrition plans [0.27\% (control) 0.52; 0.77 and $1.02 \%$ of tryptophan] with six replicates and eight birds per cage. Performance (feed intake, body average weight gain, feed conversion ratio), mortality rate and physiological parameters (heterophil/lymphocyte ratio) and corticosterone blood plasma were evaluated. In the lay period, another 192 Japanese quails were allotted to a completely randomized design in a four nutrition plans [0.23\% (control); $0.48 ; 0.73$ and $0.98 \%$ of tryptophan] with six replicates and eight birds per cage. Performance (feed intake, egg production, feed conversion ratio/egg dozen), mortality rate and physiological parameters (heterophil/lymphocyte ratio) and corticosterone blood plasma was evaluated. The tested tryptophan levels did not affect performance and physiological parameters of Japanese quails in the rearing and laying phases.
\end{abstract}

Key Words: corticosterone, Coturnix coturnix japonica, hererophil/lymphocyte ratio, performance, stress

\section{Introdução}

A criação de codornas aumentou significativamente no Brasil desde sua implantação como atividade avícola exploradora. Esse sucesso está relacionado à qualidade excepcional e ao alto valor nutritivo da carne e dos ovos desta espécie, que tem boa aceitação no mercado consumidor (Murakami \& Ariki, 1998).
Na década de 90, os mercados atacadistas e varejistas iniciaram a comercialização de ovos de codorna em conserva, o que agregou valor e aumentou o consumo desse produto em churrascarias, bares e restaurantes (Fujikura, 2002). Além disso, a facilidade de manejo e o baixo investimento inicial estimulam a criação de codornas como uma fonte de renda alternativa para famílias rurais. No entanto, um fato preocupante da criação de codornas 
é o comportamento agitado desta espécie, que resulta em muitos ferimentos nas aves. Na Europa, ferimentos na cabeça causados por bicadas são considerados problemas importantes de bem-estar na criação (Wechsler \& Schmid, 1998). Estes ferimentos na cabeça são freqüentes na criação de codornas em gaiolas, assim como outros que ocorrem quando as aves pulam e batem no topo da gaiola (Cheng, 2002).

As agressões ocorrem tanto em condições de criação intensiva como em pequenos grupos de codornas mantidas em sistema semi-intensivo (Schmid \& Wechsler, 1997) e podem resultar em sérios ferimentos, alta mortalidade e grande variabilidade na produção (Jones \& Mills, 1999).

Estudo realizado por Shea et al. (1990) com matrizes pesadas comprovou que o fornecimento de altos níveis de triptofano reduz efetivamente a agressão nestas aves. Esses autores forneceram a reprodutores machos pesados três níveis de triptofano: 0,19 (controle); 0,75 e 1,50\% e concluíram que este aminoácido diminuiu significativamente as agressões entre as aves.

Laycock \& Ball (1990) observaram redução do comportamento de histeria em matrizes leves após oito dias do fornecimento de $5 \mathrm{~g}$ de triptofano na dieta. O triptofano é um aminoácido essencial para aves, pois está envolvido em várias funções metabólicas. É um componente estrutural de todas as proteínas, além de ser precursor da síntese de serotonina e melatonina (Corzo et al., 2005)

Muitos estudos comprovaram o envolvimento do triptofano no sistema serotonérgico (5-hidroxitriptofano) sobre o desempenho e o comportamento anormal tanto em animais como no homem (Van Hierden et al., 2004). Pouco se sabe sobre o efeito do triptofano sobre o desempenho e o comportamento agressivo de codornas japonesas. Considerando que o aumento crescente da população é um fato preocupante, a produção em larga escala de ovos e carne de codorna constitui uma alternativa de produção de alimento de alto valor protéico (Murakami, 1991).

Assim, foram realizados dois experimentos com o objetivo de avaliar o efeito do nível de triptofano sobre o desempenho (consumo de ração, ganho de peso, conversão alimentar, mortalidade e produção de ovos) e os parâmetros fisiológicos (níveis de corticosterona e relação heterófilos/linfócitos) de codornas japonesas nas fases de recria e postura.

\section{Material e Métodos}

Os experimentos foram realizados no período de 30 a 44 dias de idade em galpão convencional de codornas localizado no Setor de Avicultura do Departamento de Zootecnia da Faculdade de Ciências Agrárias e Veterinárias de
Jaboticabal. Utilizaram-se codornas japonesas de 1 dia de idade criadas sobre piso coberto com maravalha no período de 1 a 25 dias de idade. As aves foram agrupadas em círculo de proteção e alimentadas com ração inicial, com a água à vontade, por meio de comedouros e bebedouros infantis para frangos de corte. O controle da temperatura foi realizado por meio de lâmpadas de infravermelho.

Aos 26 dias de idade, as codornas foram transferidas para gaiolas de postura $(32 \times 36 \times 16 \mathrm{~cm})$, dispostas em degraus. Os bebedouros utilizados foram do tipo nipple e a ração foi fornecida em comedouro tipo calha de chapa galvanizada.

Aos 30 dias de idade, depois da adaptação, 192 codornas com $97,5 \pm 12,5$ g de peso vivo foram distribuídas em delineamento de blocos casualizados e submetidas a quatro planos de nutrição $(0,27$ - controle; 0,$52 ; 0,77$ ou $1,02 \%$ de triptofano), com seis repetições e oito aves por parcela. As rações foram formuladas para serem isonutritivas, considerando a composição dos ingredientes descrita por Rostagno et al. (2000) e as exigências nutricionais relatadas por Murakami (1991), exceto quanto aos níveis de triptofano (Tabela 1).

As aves e as rações foram pesadas no início e no final da fase de recria para avaliação do consumo de ração, do ganho de peso e da conversão alimentar. Nesta fase, também foi realizado o registro da taxa de mortalidade.

Aos 37 e 42 dias de idade, foram coletadas amostras de sangue de duas aves por parcela, por punção da veia branquial e com uso de seringa heparinizada, totalizando 48 amostras semanais. Uma pequena amostra de sangue foi utilizada para a confecção das lâminas para contagem de heterófilo e linfócito. A relação heterófilo/linfócito foi realizada de acordo com o descrito por Campo \& Dávila (2002). Nesta metodologia, 100 leucócitos, inclusive os granulares (heterófilo, eosinófilo e basófilo) e não-granulares (linfócito e monócito), foram contados de cada lâmina de sangue e a relação heterófilo/linfócito foi calculada. A amostra de sangue restante foi centrifugada e o plasma obtido foi congelado a $-20^{\circ} \mathrm{C}$ para posterior avaliação dos níveis de corticosterona por meio de radioimunoensaio, conforme metodologia descrita por Malheiros et al. (2003).

Após a coleta e tabulação dos dados, as análises estatísticas foram realizadas utilizando-se o programa Estat e as médias das variáveis foram comparadas pelo teste Tukey $(\mathrm{P}<0,05)$.

Independentemente do experimento na fase de recria, outras aves foram alimentadas com ração comercial (sem adição de triptofano) até os 44 dias de idade. Quando completaram 45 dias de idade, 192 codornas japonesas foram distribuídas em delineamento de blocos ao acaso 
Tabela 1 - Composição das rações fornecidas às aves nas fases de recria e postura em cada tratamento

\begin{tabular}{|c|c|c|c|c|c|c|c|c|}
\hline \multirow[t]{2}{*}{ Ingrediente } & \multicolumn{8}{|c|}{ Plano de nutrição } \\
\hline & \multicolumn{8}{|c|}{$\%$ triptofano } \\
\hline Milho & 55,42 & 54,89 & 54,36 & 53,83 & 63,58 & 63,33 & 63,08 & 62,54 \\
\hline Farelo de soja (44\%) & 30,16 & 30,26 & 30,36 & 30,46 & 27,70 & 27,70 & 27,70 & 27,80 \\
\hline Fosfato bicálcico & 1,86 & 1,86 & 1,86 & 1,87 & 0,30 & 0,30 & 0,30 & 0,30 \\
\hline Calcário calcítico & 0,67 & 0,67 & 0,67 & 0,66 & 4,86 & 4,86 & 4,86 & 4,86 \\
\hline $\mathrm{Sal} / \mathrm{NaCl}$ & 0,30 & 0,30 & 0,30 & 0,30 & 2,60 & 2,60 & 2,60 & 2,60 \\
\hline Suplemento mineral e vitamínico & $0,50^{1}$ & $0,50^{1}$ & $0,50^{1}$ & $0,50^{1}$ & $0,12^{2}$ & $0,12^{2}$ & $0,12^{2}$ & $0,12^{2}$ \\
\hline Lisina (99\%) & 0,32 & 0,32 & 0,32 & 0,31 & 0,27 & 0,27 & 0,27 & 0,27 \\
\hline Triptofano (98\%) & - & 0,25 & 0,50 & 0,76 & - & 0,25 & 0,50 & 0,76 \\
\hline PB (\%) & 20,00 & 20,00 & 20,00 & 20,00 & 18,00 & 18,00 & 18,00 & 18,00 \\
\hline $\mathrm{Ca}(\%)$ & 0,80 & 0,80 & 0,80 & 0,80 & 2,50 & 2,50 & 2,50 & 2,50 \\
\hline P disponível (\%) & 0,45 & 0,45 & 0,45 & 0,45 & 0,55 & 0,55 & 0,55 & 0,55 \\
\hline Metionina + cistina (\%) & 0,65 & 0,65 & 0,65 & 0,65 & 0,71 & 0,71 & 0,71 & 0,71 \\
\hline Lisina (\%) & 1,30 & 1,30 & 1,30 & 1,30 & 1,15 & 1,15 & 1,15 & 1,15 \\
\hline Triptofano (\%) & 0,27 & 0,52 & 0,77 & 1,02 & 0,23 & 0,48 & 0,73 & 0,98 \\
\hline \multicolumn{9}{|c|}{ 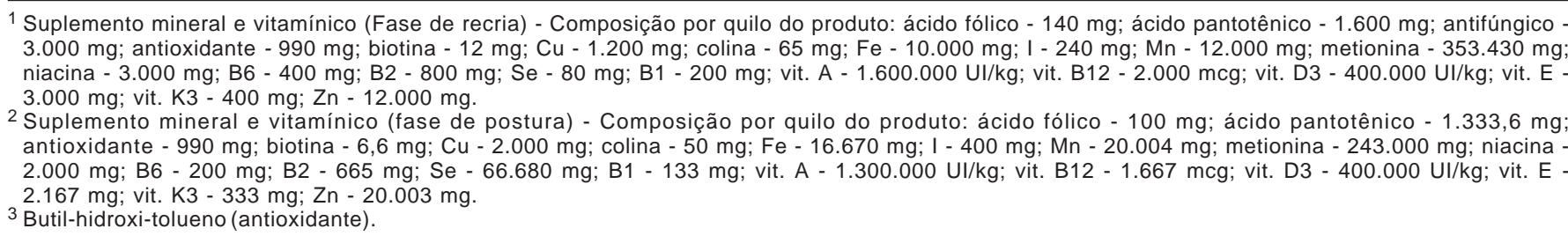 } \\
\hline
\end{tabular}

para controle do peso $(135 \pm 13,5)$ e submetidas a quatro planos de nutrição ( 0,23 [controle]; 0,$48 ; 0,73$ ou $0,98 \%$ de triptofano, Tabela 1), cada um com seis repetições e oito aves por parcela. As aves foram alojadas nas mesmas gaiolas utilizadas na fase de recria. Os bebedouros utilizados foram do tipo nipple e a ração foi fornecida em comedouro tipo calha de chapa galvanizada.

Quando as aves atingiram 5\% de produção, o período de luz foi aumentado gradativamente até completar 17 horas luz/dia.

O primeiro ciclo teve início quando as aves atingiram 50\% de produção. A partir daí, a cada 14 dias, estabeleceu-se um novo ciclo até completar seis ciclos. A cada fechamento de ciclo, foi realizada a pesagem das sobras de ração de cada repetição para controle do consumo de ração. A produção de ovos foi anotada diariamente.

Como parâmetros de desempenho, foram avaliados o consumo de ração, a conversão alimentar (consumo de ração/dúzia de ovos), a taxa de mortalidade e a produção de ovos. Aos 51, 99 e 145 dias de idade, foram coletadas amostras de sangue de duas aves por parcela, totalizando 48 amostras por coleta, para avaliação dos níveis de corticosterona (Malheiros et al., 2003) e da relação heterófilo/ linfócito (Campo \& Dávila, 2002), como descrito no experimento da fase de recria.

As análises estatísticas dos parâmetros de desempenho foram realizadas utilizando-se o programa Estat e as médias das variáveis foram comparadas pelo teste Tukey $(\mathrm{P}<0,05)$.

\section{Resultados e Discussão}

$\mathrm{Na}$ fase de recria, não ocorreu mortalidade e os resultados de desempenho não diferiram significativamente (Tabela 2). Resultado de ganho de peso semelhante foi observado por Savory et al. (1999), que submeteram galinhas poedeiras de 4 a 6 semanas de idade a dietas suplementadas com triptofano e não observaram diferença significativa no ganho de peso médio. Entretanto, em estudo com frangos de corte alimentados com dieta suplementada com $1 \mathrm{mg}$ de triptofano/kg de ração, Amano et al. (1988) verificaram aumento do consumo de ração e do ganho de peso.

Newberry \& Blair (1993) relataram efeito positivo da suplementação de triptofano sobre a carcaça de frangos de 
corte alimentados com dietas suplementadas com 0,4\% de triptofano. Do mesmo modo, Shea-Moore et al. (1996) postularam que a suplementação de triptofano em doses viáveis e não-tóxicas aumentou a uniformidade do peso corporal, diminuiu a mortalidade e melhorou a conversão alimentar de reprodutores machos.

Neste estudo, os parâmetros fisiológicos de avaliação do estresse, relação heterófilo/linfócito e concentração plasmática de corticosterona, não diferiram significativamente entre os níveis de triptofano avaliados, o que está de acordo com os resultados obtidos por Corzo et al. (2005), ao avaliarem o efeito do triptofano sobre o crescimento e o estresse de frangos de corte de 1 a 20 dias de idade. Variáveis como a relação heterófilo/linfócito e a concentração de corticosterona, que são altamente correlacionadas ao estresse, foram medidas e os resultados obtidos não diferiram significativamente entre as aves que receberam a dieta controle e aquelas com níveis reduzidos de triptofano.

Al-Murrani et al. (1997), em experimento com aves domésticas, verificaram que a relação heterófilo/linfócito deve ser usada para selecionar aves resistentes ao estresse calórico e a outros tipos de estresse, inclusive doenças. Assim, Alodan \& Mashaly (1996) verificaram aumento da relação heterófilo/linfócito no sangue de galinhas poedeiras em muda forçada e comprovaram que as aves estavam sob alto nível de estresse.

Segundo Gross \& Siegel (1983), a concentração de corticosterona no plasma é utilizada como parâmetro para medir o estresse em frangos, entretanto, McFarlane \& Curtis (1989) não observaram alterações significativas em estudo realizado com frangas sob diversas formas de estresse, como alta concentração de amônia no ar, debicagem, coccidiose, choque elétrico, estresse calórico e barulho. Os resultados obtidos para os coeficientes de variação dos parâmetros fisiológicos avaliados foram elevados, fato relacionado às respostas hormonais, que apresentaram valores muito instáveis, com coeficiente de variação acima de 30\% (Sampaio, 1998).
Os resultados obtidos na fase de postura indicam que os níveis de triptofano não tiveram efeito significativo $(\mathrm{P}>0,05)$ sobre os parâmetros de desempenho avaliados (Tabela 3). Em experimento com galinhas poedeiras comerciais, Rech (2004) descreveu que o aumento dos níveis de triptofano na dieta reduziu a produção dos ovos e não foram suficientes para eliminar os efeitos deletérios das altas densidades de alojamento.

Em experimento realizado por Ohtani et al. (1989) com galinhas poedeiras no período de 25 e 42 semanas, não foram observadas diferenças significativas entre os efeitos dos níveis de triptofano, todavia, neste mesmo experimento, as poedeiras que receberam os maiores níveis de triptofano apresentaram aumento na produção de ovos no período de 53 a 82 semanas de idade.

Lacy et al. (1986) verificaram que galinhas poedeiras com 16 semanas de idade alimentadas com rações com diferentes níveis de triptofano (2,5; 25; 50; e 100 mg) e uma solução salina controle reduziram a ingestão do alimento à medida que os níveis de triptofano foram aumentados, indicando que, dependendo do nível, o triptofano pode prejudicar o desempenho das aves. Resultado contrário foi obtido por Van Hierden et al. (2004), que avaliaram o tempo de alimentação de frangas da linhagem White Leghorn alimentadas com ração controle, com $0,14 \%$ de triptofano, ou suplementada com $2 \%$ de triptofano. As aves cuja dieta foi suplementada com triptofano apresentaram maior tempo de alimentação, que pode ser explicado pelo fato de o triptofano ser precursor do 5-hidroxitriptofano, responsável pela regulação da fome e da saciedade.

Em trabalho realizado com aves domésticas, Jones et al. (1988) concluíram que o aumento dos níveis de corticosterona não somente altera o perfil hematológico como também predispõe as aves a reagirem com mais agressividade quando estimuladas.

O estresse induzido por bicadas foi avaliado por Van Hierden et al. (2004) em frangas da linhagem White Leghorn alimentadas com dietas com e sem triptofano antes da

Tabela 2 - Desempenho e parâmetros fisiológicos de codornas japonesas na fase de recria alimentadas com rações com diferentes níveis de triptofano

\begin{tabular}{|c|c|c|c|c|c|c|}
\hline & \multicolumn{4}{|c|}{ Nível de triptofano (\%) } & $\mathrm{F}$ & CV (\%) \\
\hline Consumo de ração (g/ave/dia) & 17,07 & 17,01 & 17,05 & 17,36 & $0,13^{\mathrm{NS}}$ & 5,56 \\
\hline Conversão alimentar (consumo/ganho peso) & 8,57 & 8,04 & 8,49 & 8,31 & $0,14^{\mathrm{NS}}$ & 18,19 \\
\hline Relação heterófilo/linfócito & 0,30 & 0,26 & 0,40 & 0,31 & $0,52^{\mathrm{NS}}$ & 56,31 \\
\hline Concentração de corticosterona (ng/mL) & 119,40 & 97,42 & 227,70 & 160,35 & $0,72^{\mathrm{NS}}$ & 109,42 \\
\hline
\end{tabular}

NS - não-significativo $(P>0,05)$. 
Tabela 3 - Desempenho e parâmetros fisiológicos de codornas japonesas na fase de postura alimentadas com rações com diferentes níveis de triptofano

\begin{tabular}{|c|c|c|c|c|c|c|}
\hline & \multicolumn{4}{|c|}{ Nível de triptofano (\%) } & $\mathrm{F}$ & CV (\%) \\
\hline Consumo de ração (g/ave/dia) & 26,26 & 25,86 & 26,44 & 26,33 & $0,68^{\mathrm{NS}}$ & 2,86 \\
\hline Conversão alimentar (consumo/dz. ovos) & 0,42 & 0,39 & 0,42 & 0,37 & $2,18^{\mathrm{NS}}$ & 10,67 \\
\hline Viabilidade (\%) & 99,33 & 99,50 & 99,67 & 99,67 & $0,21^{\mathrm{NS}}$ & 0,85 \\
\hline Relação heterófilo/linfócito & 0,72 & 0,81 & 0,57 & 0,59 & $2,83^{\mathrm{NS}}$ & 24,84 \\
\hline
\end{tabular}

NS - não-significativo $(P>0,05)$.

retirada de sangue. Os resultados comprovaram que a dieta com triptofano promoveu aumento significativo dos níveis de corticosterona nas aves com baixa incidência de bicadas. Além disso, as aves com alta incidência de bicadas ficaram mais ativas com o fornecimento do triptofano.

McFarlane \& Curtis (1989) testaram simultaneamente diversas situações de estresse em frangas e não observaram diferenças na relação heterófilo/linfócito quando as aves foram submetidas a debicagem, coccidiose e barulho, no entanto, observaram aumento da porcentagem de heterófilo e diminuição concomitante da porcentagem de linfócito quando as aves foram expostas ao estresse causado pelo calor, pela concentração de amônia do ar e por choque elétrico. A relação heterófilo/linfócito também não foi afetada em experimento para avaliação do efeito do fotoperíodo na relação heterófilo/linfócito de frangos (Campo \& Dávila, 2002).

Assim como na fase de recria, os parâmetros fisiológicos da fase de postura apresentaram alto coeficiente de variação, uma vez que envolvem ação hormonal (Sampaio, 1998).

\section{Conclusões}

Os níveis de triptofano utilizados não têm efeito significativo sobre o desempenho e os parâmetros fisiológicos de codornas nas fases de recria e postura. Assim, em planos alimentares com mesmos níveis nutricionais de proteína e energia, podem ser utilizados os níveis de $0,27 \%$ (para a fase de recria) e $0,23 \%$ de triptofano (para a fase de postura).

\section{Agradecimento}

À Fundação de Amparo à Pesquisa do Estado de São Paulo, pela concessão da bolsa de Iniciação Científica e pelo financiamento do projeto, e à Profa. Dra. Alice Eiko Murakami, da Universidade Estadual de Maringá, pela doação das codornas experimentais.

\section{Literatura Citada}

AL-MURRANI, W.K.; KASSAB, A.; AL-SAM, H.Z. et al. Heterophil/lymphocyte ratio as a selection criterion for heat resistance in domestic fowls. British Poultry Science, v.38, p.159-163, 1997.

ALODAN, M.A.; MASHALY, M.M. Effect of induced molting in laying hens on production and immune parameters. Poultry Science, v.78, p.171-177, 1996.

AMANO, S.; SAITOH, S.; TANJI, K. et al. Effect of dietary tryptophan on performance and abdominal fat accumulation in broiler chicks. Japanese Poultry Science, v.25, p.176-177, 1988.

CAMPO, J.L.; DÁVILA, S.G. Influence of mating ratio and group size on indicators of fearfulness and stress hens and cocks. Poultry Science, v.81, p.1099-1103, 2002.

CORZO, A.; KIDD, M.T.; THAXTON, J.P. et al. Dietary tryptophan effects on growth and stress responses of male broiler chicks. British Poultry Science, v.46, p.478-484, 2005.

CHENG, K.M. Reprodução de codornas: onde estamos indo? In: SIMPÓSIO INTERNACIONAL DE COTURNICULTURA, 1. 2002, Lavras. Anais... Lavras: NECTA/UFLA, 2002. (CD-ROM).

FUJIKURA, W.S. Situação e perspectivas da coturnicultura no Brasil. In: SIMPÓSIO INTERNACIONAL DE COTURNICULTURA, 1. 2002, Lavras. Anais... Lavras: NECTA/UFLA, 2002. (CDROM).

GROSS, W.B.; SIEGEL, H.S. Evaluation of the heterophil/ lymphocyte ratio as a measure of stress in chickens. Avian Disease, v.27, p.972-979, 1983.

JONES, R.B.; MILLS, A.D. Divergent selection for social reinstatement behaviour in japanese quail: effects on sociality and social discrimination. Poultry and Avian Biology Review, v.4, p.213-223, 1999.

JONES, R.B.; BEUVING, G.; BLOKHUIS, H.J. Tonic immobility and heterophil/lymphocyte responses of the domestic fowl to corticosterone infusion. Physiology Behavior, v.42, p.249253, 1988.

LACY, M.P.; Van KREY, H.P.; SHEWES, P.A. et al. Intraperitoneal injections of tryptophan inhibit food intake in the fowl. Poultry Science, v.65, p.786-788, 1986.

LAYCOCK, S.R.; BALL, R.O. Alleviation of hysteria in laying hens with dietary tryptophan. Canadian Journal Veterinary Research, v.54, p.291-295, 1990.

MALHEIROS, R.D.; MORAES, V.M.B.; COLliN, A. et al. Free diet selection by broilers as influenced by dietary macronutrients ratio and corticosterone supplementation. 1. Diet selection, organ weights, and plasma metabolites. Poultry Science, v.82, p.123-131, 2003.

McFARLANE, J.M.; CURTIS, S.E. Multiple concurrent stressors in chicks. 3. Effects on plasma corticosterone and the heterophil:lymphocyte ratio. Poultry Science, v.68, p.522527, 1989.

MURAKAMI, A.E. Níveis de proteína e energia em dietas de codornas japonesas (Coturnix coturnix japonica) nas fases 
de crescimento e postura. Jaboticabal: Universidade Estadual Paulista, 1991. 92p. Tese (Doutorado em Zootecnia) Universidade Estadual Paulista, 1991.

MURAKAMI, A.E.; ARIKI, J. Produção de codornas japonesas. São Paulo: Funep, 1998. 79p.

NEWBERRY, R.C.; BLAIR, R. Behavioral responses of broiler chickens to handling: effects of dietary tryptophan and two lighting regimens. Poultry Science, v.72, p.1237-1244, 1993.

OHTANI, H.; SAITOH, S.; OHKAWARA, H. et al. Production performance of laying hens fed L-tryptophan. Poultry Science, v.68, p.323-326, 1989.

RECH, O.A. Densidade de alojamento e triptofano na alimentação de poedeiras comerciais. Londrina: Universidade Estadual de Londrina, 2004. 41p. Dissertação (Mestre em Ciência Animal) - Universidade Estadual de Londrina, 2004.

ROSTAGNO, H.S.; ALBINO, L.F.T.; DONZELE, J.L. et al. Composição de alimentos e exigências nutricionais: tabelas brasileiras para aves e suínos. Viçosa, MG: Editora UFV, 2000. 186p.

SAMPAIO, I.B.M. Estatística aplicada à experimentação animal. Belo Horizonte: Fundação de Ensino e Pesquisa em Medicina Veterinária e Zootecnia, 1998. 221p.
SAVORY, C.J.; MANN, J.S.; MACLEOD, M.G. Incidence of pecking damage in growing bantams in relation to food form, group size, stocking density, dietary tryptophan concentration and dietary protein source. British Poultry Science, v.40, p.579584, 1999.

SCHMID, I.; WECHSLER, B. Behaviour of japanese quail (Coturnix japonica) kept in semi-natural aviaries. Applied Animal Behaviour Science, v.55, p.103-112, 1997.

SHEA, M.M.; MENCH, J.A.; THOMAS, O.P. The effect of dietary tryptophan on agressive behavior in developing broiler breeder males. Poultry Science, v.69, p.1664-1669, 1990.

SHEA-MOORE, M.M.; THOMAS, O.P.; MENCH, J.A. Decreases in aggression in trytophan-supplemented broiler breeder males are not due to increases in blood niacin levels. Poultry Science, v.75, p.370-374, 1996.

Van HIERDEN, Y.M.; KOOLHAAS, J.M.; KORTE, S.M. Chronic increase of dietary L-tryptophan decreases gentle feather pecking behaviour. Applied Animal Behaviour Science, v.89, p.71-84, 2004.

WECHSLER, B.; SCHMID, I. Agressive pecking by males in breeding groups of Japanese quail (Coturnix japonica). British Poultry Science, v.39, p.333-339, 1998. 